\title{
La imagen "distorsionada": sobre la relación entre perdón y deformidad en los textos Walter Benjamin
}

\author{
Daniel R. Esparza \\ Columbia University
}

Resumen: La imagen del jorobado que aparece aquí y allá en el corpus benjaminiano, una imagen que el mismo Benjamin califica como el prototipo de la distorsión ("dem Urbilde der Entstellung") es también el prototipo del sujeto necesitado de perdón. Una lectura crítica de los lugares en los que Benjamin refiere a esta "imagen distorsionada" ofrece la posibilidad de levantar una teoría del perdón (e, indirectamente, de la culpa y de la justicia) que no reduce el perdón a una forma jurídica, a una particular dinámica emocional, o a un intercambio de condiciones morales, sino que la dota además de una clara dimensión corporal que está simplemente ausente en la mayoría de las consideraciones a propósito del perdón desarrolladas en el siglo XX.

Palabras clave: distorsión; Walter Benjamin; jorobado; perdón

Abstract: "Distorted Picture: on the Relationship Between Forgiveness and Deformity on Walter Benjamin's Worka". The hunchback we find here and there in Benjaminian texts, an image that Benjamin himself describes as the prototype of the distortion ("dem Urbilde der Entstellung") is also the prototype of the subject in need of forgiveness. A critical reading of the places in which Benjamin refers to this "distorted image" offers the possibility of raising a theory of forgiveness (and, indirectly, of guilt and justice) that does not reduce forgiveness to a legal form, to some specific emotional dynamics, or to an exchange of moral conditions. Instead, I argue the Benjaminian hunchback endows our common understandings of forgiveness with a clear bodily dimension that is simply absent in most contemporary considerations of the matter.

Keywords: distortion; Walter Benjamin; hunchback; forgiveness 
Pocas veces encontramos a Walter Benjamin escribiendo explícitamente sobre el perdón. No podemos decir lo mismo sobre la culpa, el pecado, o la Caída -así, con mayúscula bíblica-. Estos tres temas son, en los textos de Benjamin, prácticamente omnipresentes. Más aun, decir que orientan las líneas generales de su obra no es una exageración. Así, es curioso ver que Benjamin solo usa la palabra "perdón" (Vergebung) en muy escasas ocasiones: apenas dos o tres veces, casi nunca. Sin embargo, es ya un lugar común repetir que su obra está empeñada en perseguir (y quizá provocar) una redención súbita, intempestiva, "violenta". ¿Pero no supone acaso la redención, ese evento mesiánico y escatológico, un paso por o hacia una especie de perdón definitivo y final? ¿O tendremos que leer esta redención benjaminiana en términos más bien de retribución y justicia, y no de misericordia?

Una lectura cuidadosa de las célebres tesis Sobre el concepto de la historia ("Über den Begriff der Geschichte") debería ser suficiente para darnos cuenta de que Benjamin no está dispuesto a canjear redención por retribución y que su posición ante la posibilidad de entender la justicia en términos exclusivamente retributivos es abiertamente hostil. ¿'A qué clase de redención apuntan sus textos, entonces, si en todo caso apuntan a alguna? En otras palabras: ¿a qué viene el Mesías, según Benjamin, cuando aparece "no solo como redentor," sino además "como vencedor del Anticristo" 1 ? ¿A cumplir la ley? ¿A poner "al hombre contra su padre y a la hija contra su madre"? (Lucas 12, 53) ¿A llamar "no a justos sino a pecadores"? (Lucas 5,32 ) ¿O son estas preguntas demasiado cristianas para el Benjamin cabalista y materialista de las iluminaciones profanas? En lo que sigue, quisiera sugerir que seguir la pista del lugar (aparentemente marginal) que Benjamin otorga al perdón puede funcionar como una importante clave hermenéutica que es preciso tomar en serio si queremos acercarnos a varias de las ideas que el autor dejó sin explicar, sugeridas, encriptadas, sueltas o dispersas en algunas de las imágenes recurrentes en su obra. Más específicamente, quisiera dedicarme a la imagen del jorobado que aparece aquí y allá en el corpus benjaminiano, una imagen que el mismo Benjamin califica como el prototipo de la distorsión ("dem Urbilde der Entstellung”2) y que yo quisiera

$C f$. Benjamin, W., Tesis de Filosofia de la Historia, VI.

2 Cf. Benjamin, W., Selected Writings, Volume 2, Part 2 (1931-1934), Harvard University Press, 2005, p. 811; Gesammelte Schriften, Band II-2, p. 430. 
proponer, extendiendo el argumento original de Benjamin, como el prototipo del sujeto necesitado de perdón.

Si bien la categoría estética de aura -una palabra que Benjamin usa en apenas cuatro textos ${ }^{3}-$ ha servido para levantar el edificio de una estética fácilmente identificable como plena y distintivamente benjaminiana. El desarrollo de lo que podríamos llamar una teoría del perdón latente, in nuce, en los textos de Benjamin -o, incluso más, de una ética benjaminiana en la que las cuestiones del perdón, la venganza, y el mesianismo encontrarian entonces su hábitat natural- es un trabajo que aún queda pendiente, a pesar de la superabundancia de literatura producida en las últimas dos o tres décadas (buena, mala, y peor) tanto sobre la obra de Benjamin como sobre su vida. Este es mi intento (bueno, malo, o peor) de comenzar o de continuar ese trabajo. Se trata de un trabajo que parece no solo necesario, sino también urgente, no porque a Benjamin se le adeude ya demasiado (como si el ánima del filósofo estuviese esperando desde el cielo de Portbou a que alguien escribiese una vez más cualquier cosa sobre su obra, como para seguir sumando páginas y páginas a aquella superabundancia) sino porque la facilidad con la que se abusa de la idea de perdón -propensos como somos hoy a sentirnos humillados y ofendidos, en nuestra actual cultura de la victimización- obliga a pensar en ella con seriedad o, mejor aun, con cierta severidad. El perdón, en efecto, no es un asunto baladí: para algunos autores (Hegel, Ricoeur, quizá Derrida) es el logro supremo de cualquier proyecto ético. Si bien pareciese (erróneamente) que todo el mundo ha escrito ya sobre el asunto -desde los autores de la Biblia, pasando por Shakespeare, hasta llegar a Kristeva y a Nussbaum, por nombrar apenas a algunos pocos ${ }^{4}$ - la reflexión de Benjamin sobre el perdón ilumina las dimensiones económicas, políticas y corporales de este asunto con una lucidez original que brilla a través, o a pesar, de la característica densidad de sus textos.

Las preguntas que la idea de perdón suscita son numerosas y deberíamos al menos introducir algunas para entender a qué responde esta originalidad que queremos ver en los pocos textos (en las escasas líneas que, eso sí, bullen

3 Esto es, en La Obra de Arte en la Era de su Reproducibilidad Técnica, la Breve Historia de la Fotografia, Experiencia y Pobreza, y el famoso ensayo sobre Baudelaire.

4 Algunos autores contemporáneos (David Konstan y Charles Griswold in capite) han señalado que lo que entendemos hoy como perdón tiene poco, acaso nada que ver, con las nociones de (proto) perdón que podemos conseguir en la literatura arcaica y clásica griegas, lo mismo que en las biblias hebrea y griega. Para estos autores, el perdón interpersonal (esto es, el perdón "contemporáneo") es una invención cuasi-kantiana, en tanto requiere de un sujeto autónomo. Antes de la llegada de la noción del sujeto autónomo kantiano, lo que tenemos son súplicas (elevadas por un súbdito) y gracias (concedidas por un soberano). 
con referencias y posibles implicaciones) en los que Benjamin habla explícitamente de este asunto, textos en los que encontramos lo mismo alusiones que conceptos, cuasi-conceptos, para-concepto, y otras tantas formulaciones fragmentarias, incompletas o potenciales. Además, tendriamos también que identificar aquellos otros textos en los que Benjamin se refiere al problema del perdón a la inversa, esto es, releer los ensayos y artículos que Benjamin dedica a la culpa, el pecado, y la deformidad. Es de esta última de la que quiero ocuparme aquí para lograr dibujar una constelación que logre comenzar a dar cuenta de la importancia que el asunto del perdón ocupa en el corpus benjaminiano. Se trata, a mi entender, de un lugar crucial pero discreto. Quizá escondido, precisamente como el célebre enano jorobado en el automatón de la Primera Tesis (una imagen a la que volveré más adelante). Quizá, por el contrario, sea el perdón la carta robada de Benjamin, escondida a plena vista. En todo caso, no deja de ser extraño que si bien existe ya un consenso a la hora de admitir que la obra de Benjamin tiene una orientación escatológica fundamental (el autor no deja de referirse al Juicio Final, a la llegada del Mesías, a la posibilidad de redención de la historia) haya tan poca literatura dedicada a la revisión del rol que la idea del perdón juega en su filosofia, en general. En este sentido, el libro de Andrew Benjamin, Working with Walter Benjamin, ocupa un lugar originalísimo al dedicar un capítulo entero a uno de los textos en los que Benjamin habla explícitamente del perdón, El significado del tiempo en el mundo moral ("Die Bedeutung der Zeit in der moralischen Welt"), texto escrito en 1921 del que, lamentablemente, no podré aquí ocuparme. De nuevo, solo puedo intentar acercarme al problema de la imagen deforme y la relación que quiero demostrar que esta "distorsión" mantiene con el perdón en algunos textos de Benjamin.

Permítaseme adelantar lo que creo es el corazón del asunto, en pocas palabras: Benjamin no solo otorga al perdón el poder de introducir en la historia un "como si", tal y como ha afirmado Arendt en sus propias reflexiones sobre el tema. Es claro que el perdón procura asumir los eventos del pasado "como si" no hubiesen ocurrido, problematizando nuestra comprensión cotidiana de la relación entre memoria y olvido. ¿Es el perdón una ficción, un reacomodo de la memoria, un modo particularísimo de articulación de memoria y afecto? ¿Supone el perdón, como ha sugerido Agamben al referirse a la amnistía ateniense, un compromiso que obliga a no hacer mal uso de la memoria?5. Estas

\footnotetext{
5 Cf. Agamben, G., Stasis: Civil War as a Political Paradigm, Edinburgo: Edinburgh University Press, 2015.
} 
son preguntas que intentaré responder $-\mathrm{O}$, al menos, repreguntar- también en lo que sigue, al menos tangencialmente. Sin embargo, además -y a diferencia de tantas otras aproximaciones al perdón que entienden este asunto como dependiente de una teoría de los sentimientos, de una práctica penitencial, de la formación de un ethos, o de un proceso legal- Benjamin otorga al perdón una clarísima dimensión material, que podríamos decir se desprende de una tradición que ha entendido al perdón en términos también económicos. Quiero sugerir en lo que sigue que esta tradición es no tanto marxista como originalmente bíblica y que sobrevive no solo en nuestra vida ordinaria, sino además -y tanto más claramente- en algunas de las palabras (piedad, gracia(s), deuda, merced, mercancía) que comúnmente entendemos están asociadas al problema que aquí nos ocupa.

El perdón ha sido comúnmente entendido en términos transaccionales -en buena medida, esto es lo que una acción sacrificial, expiatoria, purificadora supone- en tanto "deja ir" una deuda contraída sin necesidad de que esta sea saldada. En efecto, podría decirse que el perdón es lo contrario de cualquier acción que procure saldar una deuda. El perdón, lejos de saldar, abandona, echa lejos, descarta lo adeudado (en efecto, esto es lo que sugieren los verbos usados en las biblias hebrea y griegas en este contexto). Desde luego, esto obliga a suponer que el perdón es pura gratuidad -¿no es esto lo que la noción cristiana de "gracia" supone, precisamente? ¿No es esto a lo que Derrida se refiere cuando habla de "perdón puro," "an-económico"6?- y a preguntarnos si un perdón entendido transaccionalmente no es más bien una especie devaluada de perdón. Por ejemplo, el vocablo inglés mercy deja ver claramente la dimensión económica del asunto, en tanto comparte la misma raíz etimológica de "mercancía", "mercado" y "mercenario". Si decidimos traducir mercy como "piedad", entonces tendremos que recordar que la raíz indoeuropea "peu" (de la que procede el latín "pius") significa "limpiar", "purificar". ¿Qué tienen que ver entonces la purificación y el pago de una deuda? ¿Es una deuda una especie de “impureza”? ¿Por qué la adquisición de una deuda tendría que hacer a alguien “impuro"? ¿Por qué pide la versión latina del Padre Nuestro no que se perdonen nuestras ofensas -como reza la traducción castellana- sino nuestras deudas, "dimitte debita nostra"? (¿Y por qué el castellano optó por traducir "debita” por “ofensa”?) ¿Por qué los textos evangélicos utilizan el griego “aphiemı”, un verbo

\footnotetext{
6 Cf. Derrida, J., On Cosmopolitanism and Forgiveness, Londres/Nueva York: Routledge, 2001, p. 28.
} 
que supone la renuncia a cobrar lo que se nos adeuda, cuando quieren hablar de perdón? Cuando Walter Benjamin afirma que el capitalismo es "probablemente la primera instancia de un culto que crea culpa y no expiación ${ }^{7 "}$ "es sabido que la palabra alemana Schuld significa a la vez culpa y deuda, una "ambigüedad demoníaca"8 - parece ser claro que alude no solo a la continuidad de la tradición bíblica - esta comprensión tradicionalmente económica del perdón que intentaré explicar un poco más detenidamente más adelante- sino además a la manera en la que esta cosmovisión permea nuestras instituciones seculares, económicas, políticas, sociales, financieras. Así, el perdón se convierte en un lugar privilegiado para pensar también en los procesos de secularización, lo mismo que en las dinámicas de desencantamiento ("Entzauberung") y reencantamiento del mundo: el perdón bíblico se convierte en categoría financiera y nuestras finanzas ocupan entonces el lugar de lo divino. Todas estas son preguntas que nos ayudan a entender, en mi opinión, el lugar desde el que Benjamin escribe sobre el perdón y que, desde luego, merecen ser objeto de estudio. Sobra decir que, por razones obvias, no podré ocuparme de ellas en este texto.

Para Benjamin -el "rabino marxista" de Eagleton- el perdón es una fuerza que se enfrenta entonces a una ambigüedad demoníaca: la de la deuda y la culpa o, más precisamente, de la deuda-culpa. Así, unidas y separadas a la vez por un guión, como para intentar mantener la ambigüedad original del alemán a la vista. ¿Cómo se supone que asume el perdón este enfrentamiento? Quisiera sugerir que, así como en el evangelio de Lucas el perdón aparece asociado no solo a la liberación de la acción demoníaca sino además a la curación de deformidades, el perdón en el que Benjamin piensa tiene la misión de disolver esta ambigüedad del demonio (Benjamin la califica literalmente de demoníaca) y de corregir la deformidad que Marx asegura es el saldo con el que el trabajo alienado y alienante paga al trabajador' ${ }^{9}$

"Es cierto," escribe Marx, "que el trabajo produce para el rico cosas maravillosas -pero para el trabajador produce miseria. Produce palacios -pero para el trabajador, casuchas. Produce belleza -pero para el trabajador, deformidad ${ }^{10}$ ". El perdón de Benjamin, quiero sugerir, estaría a cargo de disolver la ambigüedad de la deuda-culpa ("Schuld") que es fruto del culto del (o al) trabajo

\footnotetext{
7 Benjamin, W., Capitalism as Religion, en: Selected Writings, Volume 1 (1913-1926), p. 288. Todas las traducciones son mías.

8 Ibid.

9 Cf. Marx, M., Manuscritos Económico-Filosóficos de 1844, en: Tucker, R. (ed.), Karl Marx, MarxEngels Reader, WW Norton \& Company, 1978, p. 73.

10 Ibid.
} 
productivo. En este contexto, no deja de ser revelador notar que Jesús sana a la mujer encorvada, "a quien Satanás tenía atada durante dieciocho largos años", precisamente en sábado -cuando se supone que no se debe trabajarcomo señalando que la labor del perdón es radicalmente diferente a la labor productiva (Lucas 13, 10-17). ¿Es entonces el perdón pura improductividad? ¿En qué medida el perdón produce o deja de producir? Más aun: ¿qué se supone que debería producir el perdón, si es que algo? Me adelanto de nuevo: quisiera suponer que para Benjamin el perdón no es un medio de producción de nada, sino el cambio una noción de valor ("value") por otra ("worth"); es el paso que va de un valor matemático, mensurable, a un valor inconmensurable. ¿Es esta entonces una de las caras de la famosa irrupción mesiánica a la que Benjamin vuelve una y otra vez? Personalmente, creo que este es el caso. Intentaré explicar por qué inmediatamente.

Como la mujer del evangelio de Lucas a la que acabo de referirme, hay en la obra de Benjamin más de una figura encorvada. En la primera de sus Tesis sobre la Historia, Benjamin recuerda al jugador de ajedrez de Maelzel de Edgar Allan Poe al comparar a la teología -esa fuerza de la que el materialismo histórico no puede prescindir, pero que bajo ningún respecto puede permitir que sea vista ${ }^{11}$ - con un enano jorobado, escondido gracias a un ingenioso juego de espejos, que guía la mano de un muñeco autómata trajeado "a la turca" para hacerle ganar cada partida. ¿No es acaso un enano jorobado y escondido una figura arquetípica de la deformidad? Para Benjamin, lo es. En su Infancia en Berlín, el autor recuerda también al "hombrecito jorobado" ("das bucklige Männlein") que según el Libro Para Niños de Georg Scheler -al que Benjamin refiere en este texto- es responsable de los accidentes domésticos y torpezas de nuestra infancia, y que se encuentra a gusto -según Benjamin- entre la canalla ("Lumpengesindel”), entre el lumpen.

Esta es, en mi opinión, una constelación que merece ser revisada: ¿cómo un enano jorobado que entiende que su lugar está junto al lumpen es responsable de accidentes domésticos, y cómo otro enano encorvado y escondido es la fuerza que logra hacer que el materialismo dialéctico resulte siempre triunfante? ¿Es el primero una fuerza demoníaca y el segundo una fuerza mesiánica? ¿Es el lumpen el lugar propio de lo teológico, al modo de la más temprana teología de la liberación? Benjamin compara claramente en su Primera Tesis al enano escondido en el automatón con la teología, "que es pequeña y fea," pero no

${ }^{11}$ Cf. Benjamin, W., Tesis de Filosofia de la Historia, I. 
dice mucho más sobre el bucklige Männlein de la rima infantil alemana. Sin embargo, en otro de los textos que también integran la Infancia en Berlín, "Die Mummerehlen", Benjamin habla del "mundo deforme de la infancia" ("die ganze entstellte Welt der Kindheit" ${ }^{12}$ ). Incluso más: en su largo texto sobre Franz Kafka en el décimo aniversario de su muerte, en el que hallamos de nuevo al infantil "hombrecito jorobado", Benjamin afirma que todas las figuras distorsionadas ("entstellt") que podemos conseguir en la obra de Kafka -desde Odradek hasta Samsa- "están conectadas a través de una larga serie de figuras con el prototipo de la distorsión ("dem Urbilde der Entstellung"): una espalda encorvada ("dem Buckligen") ${ }^{13}$. Quiero sugerir que, en esta frase, que define una espalda encorvada como "prototipo de la distorsión," se encuentra el corazón del argumento benjaminiano sobre el perdón. Y si no el corazón, al menos un órgano vital; o su columna vertebral, obviamente encorvada.

En efecto, continúa Benjamin, "entre las imágenes kafkianas, ninguna es más frecuente que aquella del hombre que inclina su cabeza hacia su pecho: la fatiga de los oficiales de la corte, el ruido que afecta a los porteros en el hotel, el techo bajo enfrentando a los visitantes de la galeria" ${ }^{14}$. La burocracia no solo deforma, parece sugerir la lectura que Benjamin hace de Kafka, sino que es en sí misma deformidad. Benjamin termina citando El Castillo y afirmando que "los funcionarios y oficiales no pueden perdonar: solo juzgar" ${ }^{15}$. ¿Qué significa esta incapacidad de perdonar que Benjamin identifica con una burocracia deformante, con un trabajo que, como sentencia el joven Marx, produce deformidad?

Toda espalda encorvada está obviamente cargada con un peso. Más aun: una espalda encorvada es en sí misma su propio peso, afirma Benjamin, citando una entrada del diario de Kafka en la que el autor cuenta cómo, para intentar dormir, procura hacerse "más pesado" abrazándose a sí mismo y quedándose alli tirado "como un soldado con su mochila"16. Inmediatamente después añade Benjamin: "es palpable que aquí el estar cargado equivale a olvidar -el olvido de un hombre que duerme"17. Las relaciones entre perdón y olvido -que no podemos cansarnos de considerar, pero de las que no podré

${ }^{12}$ Cf. Benjamin, W., Die Mummerehlen, Gesammelte Schriften, Band IV-1, pp 260-263.

${ }^{13}$ Cf. Benjamin, W., Selected Writings, Volume 2, Part 2 (1931-1934), p. 811; Gesammelte Schriften, Band II-2, p. 430.

${ }^{14}$ Cf. Benjamin, W., Selected Writings, Volume 2, Part 2 (1931-1934), p. 811; Gesammelte Schriften, Band II-2, pp. 430-431.

${ }^{15}$ Ibid.

${ }^{16}$ Cf. Benjamin, W., Selected Writings, Volume 2, Part 2 (1931-1934), p. 811; Gesammelte Schriften, Band II-2, p. 431.

17 Ibid. 
ocuparme aquí in extenso por razones, precisamente, de extensión- son sin duda complejas, y lo son tanto más si se le añade a esta ya tirante relación una dimensión onírica, como Benjamin parece querer hacer al referir al olvido "de un hombre que duerme". Sin embargo, debe quedar claro al menos que Benjamin afirma que estar cargado y olvidar son una y la misma cosa: el olvido es un fardo. ¿Es la memoria, entonces, una "carga ligera” como la del Evangelio? (Mateo 11, 29-30). Esto parece ser contraintuitivo, especialmente si tomamos en cuenta que comúnmente suponemos que el perdón supone alguna forma de olvido. Que nos sintamos incómodos cuando alguien repite que "perdona, pero no olvida" parece confirmar que popularmente se supone que el perdón no es memorioso, que es una especie de subgénero del olvido, y que el perdón está en las antípodas de la memoria. Pero Benjamin parece estar aquí diciendo precisamente lo contrario, a saber, que el perdón es en sí mismo una forma -o una dimensión, o un aspecto- de lamemoria, que no hay perdón sin memoria y, quizá incluso más radicalmente, que no hay memoria sin perdón. ¿No ha intentado el psicoanálisis una y otra vez demostrar que las dinámicas del trauma son inconscientes precisamente en tanto no se han resuelto?

En ese sentido, el perdón implica una especie de descenso en y hacia el trauma, hacia la tragedia, hacia el dolor: se trata de una deliberada (re)visita y (re)visión del evento traumático. Sobre esta relación entre perdón y memoria -y, por consiguiente, sobre la permanencia del evento traumático, de la tragedia, de las catástrofes que Benjamin asegura siguen apilándose una sobre otra ante la mirada aterrorizada del ángel de la historia ${ }^{18}$ - quisiera agregar aquí un detalle "teológico": así como en el cuerpo resucitado permanecen las llagas de la Pasión -ha sido el propio Benjamin quien ha dicho que hay que tomar a la teología a nuestro servicio, y es esto lo que procuro hacer con esta(s) referencia(s)- el perdón supone la memoria -una memoria que quiero llamar "trágica" o "sufriente," una especie de memoria passionis à la Metz-como su condición de posibilidad. Esta dimensión anamnética-trágica es una instancia más en la que la intima relación (o distinción) existente entre sacrificio y perdón se revela. ¿Qué clase de sacrificio puede tener Benjamin en mente, si es que alguno? ¿Qué se debe sacri-ficar, hacer sagrado, destinar a la muerte, separar del resto? Peor aun: ¿la deuda-culpa demoníaca a la que Benjamin refiere debe pagarse sacrificialmente, o debe el perdón más bien evitar el sacrificio de sangre que supone la cancelación de una deuda, como en el caso paradigmático del Mercader de Venecia?

${ }^{18}$ Cf. Benjamin, W., Tesis de Filosofia de la Historia, IX. 
Volvamos un momento a la "carga" que Benjamin señala. Decíamos, siguiendo a Benjamin, que la "carga" es entonces una forma de olvido. ¿Pero un olvido de qué? ¿De qué se trata el olvido "de un hombre que duerme"? Quiero tomarme la libertad de asociar esta imagen, de nuevo, con otro texto bíblico.

En la Biblia, la gente se queda dormida-y sueña-constantemente. A José le habla un ángel en sueños para convencerle de no abandonar a María; Jacob sueña con una escalera al cielo; Daniel y José (el hijo de Jacob) interpretan sueños; los apóstoles se quedan dormidos mientras Jesús ora en Getsemaní; y las vírgenes prudentes a las que refiere Mateo (Mt 25, 1-13), a pesar de haberse quedado dormidas, conservaron suficiente aceite en sus lámparas como para mantenerlas encendidas hasta que llegó el novio y lograron entrar al banquete nupcial. ¿No es este "quedarse dormido" una señal de haber abandonado la especial expectativa que se supone se debe mantener ante la posibilidad constante de la llegada del Mesías? ¿Y no es precisamente el Mesías quien tiene la autoridad-escandalosa, conflictiva-de perdonar los pecados? ¿Y no nos ha sido dada a nosotros también -afirma Benjamin- "una flaca fuerza mesiánica sobre la que el pasado exige derechos?"19. De esta flaca fuerza mesiánica, quisiera sugerir, depende cualquier articulación posible de memoria y perdón, y, en consecuencia, cualquier acción política que suponga alguna forma de justicia histórica, bien sea que venga esta en forma de retribución o de amnistía. La pregunta obligada parece ser siempre la misma: ¿Qué vamos a hacer con nuestros pasados culposos, con nuestras culpas hereditarias, con la memoria de nuestros males, pero también con nuestra flaca capacidad no de sentirnos ofendidos, sino más bien de perdonar?

Si Gary Anderson tiene razón -yo, personalmente, creo que la tienecuando afirma, en su History of Sin, que este "estar cargado" es una de las tres maneras en las que la Biblia entiende el pecado -"cuando uno peca, algo concreto ocurre: nuestras manos se manchan, una carga es puesta sobre nuestras espaldas, uno contrae una deuda"20 - entonces es claro que en estos textos Benjamin está dibujando una especie de fenomenología del pecado manteniendo un ojo en la tradición bíblica. Esto no supone ninguna novedad: es sabido que esto es precisamente lo que Benjamin siempre hizo. Si bien la deformidad que es consecuencia de este fardo provee al pequeño enano jorobado de una vida distorsionada ("entstellten Lebens") en la que este se siente "en casa," Benjamin

${ }^{19}$ Cf. Benjamin, W., Tesis de Filosofia de la Historia, II.

${ }^{20}$ Anderson, G., History of Sin, New Haven/Londres: Yale University Press, 2009, p. 4. 
afirma que "(el enano) desaparecerá con la llegada del Mesias, quien (dijo alguna vez un gran rabino) no cambiará el mundo a la fuerza sino que apenas le hará un pequeño ajuste"21. Quiero proponer, para responder las preguntas que he planteado hasta ahora, que para Benjamin la llegada del Mesías, el momento de la redención, implica la destrucción -la "desaparición", el "ajuste"- de esta deformidad, precisamente como ocurre en el pasaje del evangelio de Lucas al que me he referido anteriormente: la sanación de la mujer encorvada. Jesús "ajusta" la espalda de la mujer encorvada del evangelio, "desapareciendo" su joroba. ¿Es este "ajuste" entonces la forma mesiánica de "justicia” o, tanto mejor, de "a-justicia", una especie de justicia negada? ¿Es este "a-juste" también una especie de "ajusticiamiento" misericordioso que entiende el perdón como la forma máxima de justicia, su clímax y su cumplimiento? Si esto es así, el perdón es entonces una especie de dispositivo de autodestrucción en el corazón de la ley, que persigue su cumplimiento a través de su aplicación en negativo: si la ley necesita ser aplicada ("enforced", puesta "en fuerza", como sugiere el inglés) para hacer cumplir la justicia, renunciar a la aplicación de la ley (bajo la forma de castigo, o del pago de la deuda) aparentemente equivale a disolver la posibilidad de hacer que la justicia se cumpla. ¿Pero no es este "ajuste" también una forma de mostrar la justicia tanto más patentemente? Quisiera sugerir aquí que el perdón, para Benjamin, solo a-justa: esto es, que tiene la capacidad de hacer justo al pecador. Le permite contemplar la justicia, como se dice en el argot taurino, "desde la barrera." El perdón establece una distancia contemplativa entre el culpable y la sentencia que le correspondería; tiene la capacidad de hacer "justo" a quien lo recibe al hacerle ver aquello de lo que se ha librado, pero desde un golfo que separa al victimario de su castigo, como quien contempla un incendio o un naufragio a lo lejos. En ese sentido, el perdón puede pensarse como la correspondencia ética de la experiencia estética de lo sublime 22 .

Para concluir, quisiera recordar que, al final de su ensayo sobre Kafka -en la sección que dedica a Sancho Panza-Benjamin afirma que poco importa si se es un hombre o un caballo, mientras que este fardo ("Last", en el alemán original) sea retirado de nuestras espaldas ${ }^{23}$. Pero, ¿cómo ocurre esta "desaparición,"

${ }^{21}$ Cf. Benjamin, W., Selected Writings, Volume 2, Part 2 (1931-1934), p. 811; Gesammelte Schriften, Band II-2, p. 431.

${ }^{22}$ Esta intuición es, en efecto, una de las facetas principales de mi propia aproximación al perdón, que me encuentro en estos momentos desarrollando en un libro dedicado al asunto.

${ }^{23}$ Cf. Benjamin, W., Selected Writings, Volume 2, Part 2 (1931-1934), p. 816; Gesammelte Schriften, Band II-2, p. 438. 
este "ajuste", este deshacerse del fardo? En su Crítica de la Violencia, Benjamin propone el modelo de una "humanidad recta" ("Gerechten Menschen") que parece ser su versión del sujeto autónomo kantiano, o del alma bella ("Schöne Seele") de Schiller y Hegel. Estas dos figuras -el jorobado y la humanidad recta- serán entonces los dos pilares sobre los que, quiero proponer, se sostiene la cuestión del perdón en Benjamin. Lo que parece dibujar la constelación que podemos construir a partir de estos pocos textos es entonces un itinerario benjaminiano del alma, que va de la distorsión -del estar encorvado- a la rectitud -el ser "recto", "Ge-rechten", "a-justado", hecho justo (en lugar de a-justiciado)-.¿Cómo se supone que recorremos ese itinerario? Esta es precisamente la pregunta que supone la creación de un sujeto moral autónomo, mayor de edad (à la Kant) o de un "alma bella" (à la Schiller). Aquí, la influencia de los autores de la Ilustración y el Romanticismo alemanes en Benjamin se ve tan claramente como en su Trauerspiel. Una investigación que entienda la posibilidad de una lectura romántica de los textos de Benjamin para construir una posible Bildung Benjaminiana, el itinerario al que he apenas aludido es, quisiera proponer, una tarea que aún queda pendiente: es una deuda (Schuld) sobre la que "el pasado exige derechos" 24 , una exigencia "que no se debe despachar a la ligera" 25.

Recibido: 06/06/2019

Aceptado: 29/12/2019

\section{Bibliografia}

Agamben, G., Stasis: Civil War as a Political Paradigm, Edinburgo: Edinburgh University Press, 2015.

Anderson, G., History of Sin, New Haven/Londres: Yale University Press, 2009.

Benjamin, W., Gesammelte Schriften, Tiedemann, R. (ed.), Fráncfort d.M., Suhrkamp, 1974.

Benjamin, W., Selected Writings, Jennings, M. (ed.), Cambridge/Londres: The Belknap Press of Harvard University Press, 2003.

Derrida, J., On Cosmopolitanism and Forgiveness, Londres /Nueva York: Routledge, 2001.

Tucker, R. (ed.), Karl Marx, Marx-Engels Reader, WW Norton \& Company, 1978.

${ }^{24}$ Cf. Benjamin, W., Tesis de Filosofía de la Historia, II.

${ }^{25}$ Cf. Benjamin, W., Tesis de Filosofia de la Historia, II. 